\title{
A MULHER NO PÓS-PARTO DOMICILIAR: UMA INVESTIGAÇÃO SOBRE ESSA VIVÊNCIA
}

\author{
The woman in the home postpartum: \\ A research about this existence \\ La mujer en el posparto domiciliario: \\ Una investigación sobre esa vivencia
}

Lucia Helena Garcia Penna

Joana labrudi Carinhanha

Raquel Fonseca Rodrigues

\begin{abstract}
Resumo
Investigamos a vivência do pós-parto domiciliar pela mulher a partir de sua percepção acerca dos sentimentos, mudanças e situações desse período. Numa abordagem qualitativa, entrevistamos oito puérperas, entre $015^{\circ}$ e $030^{\circ}$ dias de pósparto, atendidas nas consulta de enfermagem de revisão puerperal numa Unidade Básica de Saúde (UBS/SMS/RJ). A técnica utilizada na análise foi a de Análise de Conteúdo, na qual emergiu as seguintes categorias: Atendimento das expectativas, Situação das Relações Interpessoais, Situação da Relação Intrapessoal (sentimentos e sensações; relação com o corpo). Constatamos que as depoentes vivenciaram o pós-parto com satisfação, porém identificamos também uma desvalorização do ser mulher e do autocuidado em prol da atenção ao recém-nascido. Percebemos a importância da participação familiar no processo maternal e a realização de um acompanhamento pós-parto que aborde os reais sentimentos desse período, o resgate da autonomia sobre si mesmas e outros aspectos da subjetividade das puérperas.
\end{abstract}

Palavras-chave: Período Pós-parto. Saúde da Mulher. Habitação. Enfermagem.

\begin{abstract}
Looked for to investigate the existence of the postpartum home for the woman starting from his/her perception concerning the feelings, changes and situations of that period. In a qualitative approach, we investigated eight women, in the 15th and 30th days of postpartum, attended in consultation of nursing of revision puerperal in the Basic Unit of Health (UBS/SMS/RJ). For analysis of the data we used the technique of content analysis, where it emerged the following categories: Service of the expectations, Situation of the Interpersonal Relationship, Situation of the Intrapersonal Relationship (feelings and sensations; relationship with the body). We verified that the witness lived the postpartum with satisfaction, however we also identified a depreciation of the being woman and of the care of herself on behalf of the attention to the newly born. We noticed the importance of the family participation in the maternal process and the accomplishment of a postpartum attendance that it approaches the real feelings of that period, of the rescue of the autonomy on themself and other aspects of the subjectivity of the women in the postpartum.
\end{abstract}

\section{Keywords:}

Period Postpartum. Woman's Health. Housing. Nursing.

\section{Resumen}

Investigamos la viviencia del post-parto domiciliario por la mujer desde su percepición sobre los sentimientos, cambios y situaciones de esto período. En un abordaje cualitativo, entrevistamos ocho puérperas, entre el $15^{\circ}$ y el $30^{\circ}$ día de post-parto, ayudadas en las consultas de enfermería de revisión puerperal en una Unidad Basica de Salud (UBS/ SMS/RJ). La tecnica usada en el analisis fué la de Analisis de Contenido, en el cual emergió las seguientes categorías: Atendimiento de las Expectativas, Situaciones de las Relaciones Interpersonais, Situaciones de Relación Intrapersonal (sentimientos y sensaciones; relación con el cuerpo). Fué constatado que las deponentes vivieron el post-parto con satisfación, pero fué indentificado también una desvaloración del ser mujer y del autocuidado en prol de la atención al recién nacido. Percebimos la importáncia de la participación de la familia en el proceso maternal y la realización de un acompañamiento post-parto que aborde los reales sentimientos de este período, el resgate de la autonomía sobre ellas mismas y otros aspectos de la subjetividad de las puerperas.

Palabras clave:

Periodo de Postparto. Salud de la Mujer. Vivienda. Enfermería. 


\section{INTRODUÇÃO}

0 pós-parto (também designado puerpério) é um período de adaptação física e emocional em que a mulher vivencia o confronto entre as expectativas construídas durante a gestação e a realidade do período após o parto. Esse trabalho investiga a vivência do pós-parto domiciliar pela mulher a partir de sua percepção acerca dos sentimentos, mudanças e situações que se apresentam nesse período.

0 interesse por esse tema surgiu de experiências na prática da assistência obstétrica que nos levaram a perceber um esforço crescente e um avanço no sentido da melhoria da assistência pré-natal e ao parto. Entretanto, sentimos que pouco se discute sobre a vivência do puerpério sob a ótica da mulher, tanto no meio científico e profissional, quanto com as próprias usuárias dos serviços, as puérperas. Além disso, a literatura existente aponta o puerpério como um período de conflito em que se alternam na mulher sentimentos de alegria, medo, alívio, ansiedade, realização, dificuldade, dúvida ${ }^{1,2,3,4}$. A Política Nacional de Atenção Integral à Saúde da Mulher ${ }^{5}$ preconiza, para a assistência à mulher, a integralidade e a promoção da saúde a partir de um enfoque de gênero. Contudo, o atendimento recebido pelas mulheres no período pósparto, em geral, é limitado aos aspectos fisiológicos como: a retirada de pontos, a verificação da involução uterina e da evolução mamária, entre outros. Despertou-nos, portanto, a preocupação acerca da autonomia e entendimento sobre o pós-parto pelas mulheres assistidas em consulta de revisão puerperal realizada pela enfermeira numa Unidade Básica de Saúde do município do Rio de Janeiro. Quer dizer, partindo dos pressupostos de que o pós-parto é um momento crítico e/ou conflitante e que as mulheres necessitam de um atendimento integral e humanizado, como as mesmas estão percebendo a vivência desse período?

Entendemos que a compreensão acerca da vivência da mulher a partir de sua visão é fundamental para que possamos avaliar sua demanda real de necessidades e, assim, estabelecer uma assistência que a atenda efetivamente em sua integralidade. Com isso, acreditamos ser possível contribuir para a melhoria da assistência puerperal, pensada como um espaço onde a mulher possa se expressar aberta e livremente, sendo valorizados as suas angústias, receios, desejos, necessidades, saberes.

\section{ASPECTOS METODOLÓGICOS}

Para a realização da pesquisa adotamos uma abordagem qualitativa ${ }^{6}$ que se apresenta como método capaz de alcançar o aspecto subjetivo do ser humano, uma vez que pretendemos compreender o objeto, partindo da realidade social das protagonistas da pesquisa.

Como campo de estudo, foi escolhida a Unidade Básica de Saúde Milton Fontes Magarão - Área Programática 3.2 do município do Rio de Janeiro (UBS/ SMS/RJ) -, onde são desenvolvidas Consultas de Enfermagem de revisão puerperal. 0 interesse por este campo de estudo emergiu do fato de que esta unidade vem possibilitando o desenvolvimento de atividades na área de ensino, assistência e pesquisa sobre diversas temáticas.

Para coleta dos dados, utilizamos a técnica da entrevista semi-estruturada que se desenrola a partir de um esquema básico, porém não aplicado rigidamente, permitindo que 0 entrevistador faça as necessárias adaptações. Considerando a entrevista como uma conversa com finalidade ${ }^{7}$, é possível obter informações subjetivas - sentimentos, experiências, opiniões, atitudes, valores, motivações - contidas nos discursos dos sujeitos. Desta maneira, o sujeito tem uma maior liberdade de discorrer sobre o tema, gerando um material mais rico.

As protagonistas sociais da pesquisa foram oito puérperas, escolhidas aleatoriamente, assistidas em consulta de enfermagem de revisão puerperal na referida UBS.

Para atender às exigências éticas e científicas fundamentais previstas na Resolução do Conselho Nacional de Saúde - CNS 196/968 sobre pesquisa envolvendo seres humanos, as mulheres assinaram 0 termo de consentimento livre esclarecido para autorizar sua participação voluntária na pesquisa. Ainda em conformidade com esta resolução, o projeto de pesquisa foi encaminhado à avaliação pelo Comitê de Ética reconhecido pela Comissão Nacional de Ética em Pesquisa e autorizado pela Diretoria da UBS Milton Fontes Magarão.

Finalmente, para a compreensão dos dados coletados, optamos pela Dialética, ${ }^{9}$ como base teóricofilosófica de interpretação dos dados e, para o tratamento destes, nos valemos da análise de conteúdo ${ }^{11}$, especificamente a análise temática.

Os textos das entrevistas, portanto, foram analisados numa discussão contextual da realidade, 
procurando o significado real da fala das mulheres e a sua relação com o seu conteúdo histórico, social e qualitativo em sua totalidade.

A análise constituiu-se, primeiramente, de uma leitura flutuante dos depoimentos a fim de tomar ciência do conteúdo dos mesmos. A seguir, definimos as unidades de registro, ou seja, os recortes dos depoimentos de significado referente ao objeto de estudo. A partir dessa separação, agrupamos as unidades de registro de significado próximo em unidades maiores, os temas ou unidades de significação, os quais foram referidos na apresentação dos resultados na forma de grifo itálico. Estes foram reorganizados em conjuntos mais abrangentes, que apresentam similaridade temática, denominadas categorias, as quais foram nomeadas em decorrência do conhecimento científico que expressam. As categorias que emergiram desse processo foram: "Atendimento das Expectativas", "Situação das Relações Interpessoais" e "Sentimentos e Sensações". Finalmente, cada categoria foi descrita, sendo realizadas inferências e interpretações previstas no seu quadro teórico.

\section{RESULTADOS E DISCUSSÃO}

As entrevistas aconteceram no momento imediatamente anterior às consultas de revisão puerperal, de forma que as depoentes contavam com um período pós-parto entre 15 e 30 dias; paridade: três primíparas e cinco multíparas; faixa etária: entre 17 e 39 anos; residência: zona norte do município do Rio de Janeiro; ocupação: "donas de casa" (5), estudante (1), atendente de padaria (1) e diarista (1).

\section{Atendimento das expectativas:}

As expectativas das puérperas acerca do pós-parto em casa foram variadas, embora tenham sido atendidas ou superadas. De acordo com a literatura, esperávamos relatos queixosos e que o puerpério fosse ser referido como repleto de dificuldades, seja pelo mito que se formou acerca desse período, seja pela desfavorecida condição sócio-econômica que dificultaria o enfrentamento da crise. Entretanto, percebemos características citadas na literatura, a exemplo do cansaço no exercício das atividades, aparecendo nos depoimentos de forma suavizada, como se fossem apenas um "pano de fundo" ou, simplesmente, não tivessem valor maior, pois o mais importante para elas é que conseguiram dar à luz um bebê saudável. Outras dificuldades são verificadas ao longo de seus depoimentos desta mesma maneira, reforçando o peso cultural da maternagem.

Acerca dessa desvalorização das dificuldades, podemos refletir sobre o fato de estarmos tratando de um puerpério ainda recente; quer dizer, as puérperas entrevistadas contavam com cerca de 15 a 30 dias de pós-parto, não havendo tempo para que as mesmas percebessem as dificuldades, embora Maldonado ${ }^{4}$ afirme que a labilidade emocional seja o padrão mais característico da primeira semana após o parto, alternando-se euforia e depressão. Os acontecimentos recentes trazem consigo uma motivação que os impulsiona de forma otimista. Entretanto, à medida que vão se tornando rotineiros, as dificuldades e entraves que lhes são intrínsecos passam a ser percebidos mais facilmente. Assim, as mulheres entrevistadas estariam ainda tomadas pela nova e grande emoção de serem mães de bebês saudáveis, relegando as dificuldades do momento.

Continuando a reflexão sobre a reduzida importância dada aos impasses no pós-parto, encontramos a questão do alojamento conjunto. Segundo Maldonado et al ${ }^{3: 68}$,

0 sistema de alojamento conjunto implica uma nova concepção do papel da maternidade que, além de prestar assistência em termos de cuidados físicos aos pacientes, assume também a função de facilitar a adaptação dos pais ao bebê, oferecendo orientação, educação [...]. Como efeitos gerais, reduz-se o nível de ansiedade da mãe, aumentando sua segurança e confiança na própria capacidade.

Tomando como base a referência supracitada, poderíamos nos questionar se o alojamento conjunto seria responsável pela identificação do puerpério domiciliar pelas entrevistadas como um momento mais tranqüilo e ajustado do que o referido comumente pela literatura. Entretanto, acreditamos que esse sistema possa assumir apenas uma parcela dessa responsabilidade, pois os depoimentos nos levam a crer na prevalência da desvalorização das situações de impasse como uma dificuldade concreta em função da necessidade de demonstrarem sua postura de "mãe perfeita" exigida sócio-culturalmente e da influência das emoções recentes e positivas do ser mãe.

As puérperas, ao descreverem o parto como um momento de dúvida no qual pouco foram orientadas sobre este processo marcante, demonstram em seus discursos, de forma implícita, os seus reflexos no puerpério. É compreensível que elas tenham a expectativa de entender a vivência do parto no 
puerpério, uma vez que este é o momento de reestruturação física, mas principalmente emocional, das alterações decorrentes do processo gravídico, incluindo o parto. Além disso, uma situação que deve estar em consonância com o enfrentamento do parto pela mulher é a necessidade de se melhorar a assistência ao parto e nascimento para que ocorram de maneira a diminuir o impacto negativo desse processo na vida da mulher e seu bebê.

Como já referido, a mulher se torna mais sensível no puerpério, de forma que o seu acolhimento pela família é imprescindível e, nos casos das entrevistadas, mostrou-se importante para as mesmas. Culturalmente, há a confraternização familiar em torno da nova vida que se insere nesse núcleo. Segundo Canteiro e Martins ${ }^{12:}$, em estudo sobre as crenças e tradições envolvidas com a maternidade, a gravidez é também um fenômeno social, onde as crenças familiares construídas e mantidas pela família ao longo do tempo se transmitem às novas gerações. A mulher no puerpério encontra-se ávida pelo sentimento de conforto, calor, justiça e proteção em decorrência da projeção imaginária quanto ao futuro estado de ser mãe e pelo próprio processo vivido durante 0 trabalho de parto ${ }^{13}$. Portanto, as visitas, que se intensificam nesse período, tornam-se momentos propícios para o acolhimento da puérpera, bem como para a perpetuação de tais crenças.

\section{Situação das Relações Interpessoais:}

Basicamente, a maioria das mulheres não apontou alteração nas relações com o parceiro, familiares e conhecidos, tendo apenas uma mulher verbalizado irritabilidade e cansaço com seus familiares. Por um lado, é importante que as puérperas percebam e mantenham uma boa relação com o parceiro $e$ familiares e recebam o apoio dos mesmos para manter o equilíbrio intra e interpessoal. Por outro lado, causanos certa estranheza as entrevistadas não terem referido alteração alguma em suas relações interpessoais, uma vez que a inserção de uma nova pessoa no núcleo familiar gera impactos positivos ou negativos em cada membro da família ${ }^{1,4}$, alterando em alguma medida a relação entre eles. Segundo Maldonado ${ }^{4}$, no caso das multíparas, seria esperado sentimentos de ciúme, traição e abandono pelos outros filhos. Entretanto, foi referido que os mesmos não tiveram dificuldade na aceitação do irmão mais novo.

Identificamos que as situações inalteradas nas relações interpessoais estão diretamente relacionadas ao recebimento de ajuda, principalmente da mãe e/ ou sogra, mas também dos filhos anteriores e empregada. Como já foi referido, o puerpério é um período de adaptação a novas rotinas e, como tal, prescinde do apoio físico e emocional para que possa ser enfrentado de forma tranqüila e saudável como parte de um processo de desenvolvimento humano. As puérperas entrevistadas mencionaram 0 recebimento desse apoio; entretanto, não podemos inferir a respeito da qualidade do mesmo. Segundo Afonso ${ }^{1}$, nos primeiros dias após o parto, a mulher/ casal pode não estar muito disponível para as visitas, que costumam ser mais freqüentes nesse período, bem como as informações contraditórias de familiares e amigos podem aumentar a angústia da mulher/casal. Maldonado et $\mathrm{a}^{\beta: 73}$ falam ainda que toda essa situação pode dificultar a intuição e capacidade de sintonizar com o filho e perceber suas necessidades. De toda sorte, dentro do grau de exigência daquelas mulheres, 0 apoio recebido foi suficiente.

Ainda sobre a participação nos cuidados do recémnascido, Afonso ${ }^{1}$ afirma que quanto menor a diferença entre o casal nessa participação, tanto menor será 0 conflito entre eles, pois compartilharão os momentos difíceis e também os gratificantes da criação de um filho. Nesse sentido, Maldonado et $a^{\beta}$ explicitam que há homens participantes, enquanto outros se sentem alheios ao filho. Assim como a mulher, o homem também se depara com conflitos que envolvem a sua paternidade. A equipe de saúde pode influenciar esse aspecto ao estimular a presença e participação do pai durante todo o processo gravídico-puerperal. Assim, é possível dar continuidade à insipiente, mas significativa, divisão da responsabilidade social pelo cuidado dos filhos entre casal.

Em relação ao afastamento do parceiro, referido por algumas entrevistadas, podemos sinalizar alguns, dentre vários fatores, que poderiam estar contribuindo para esta conduta ${ }^{1}{ }^{4}$ : (a) ciúme da companheira por estar dividindo sua atenção com o bebê; (b) intensificação no ritmo de trabalho do parceiro, seja no sentido de aumentar a renda familiar, seja como fuga da relação dual entre mãe e filho, na qual não está ou não se sente incluído; (c) sensibilização acentuada da puérpera em função do momento pelo qual está passando e que dificulta a compreensão da mesma acerca dos conflitos que estão se apresentando com o parceiro; (d) medo do parceiro de machucar a puérpera ou da falta de desejo da mesma para a troca de afetos. Tratam-se de situações em que se faz necessário muito diálogo franco e aberto entre o casal no sentido de um tomar conhecimento do que o outro 
está sentindo ou pensando para que possam ajudarse mutuamente e mesmo aprofundar mais a relação ${ }^{14}$. 0 profissional de saúde, por sua vez, precisa estar atento e dedicar atenção ao estímulo a uma relação dialógica entre o casal. Vale ressaltar a importância dessa conduta a partir do pré-natal, a fim de que o casal esteja sensibilizado para 0 impacto que a gravidez e o parto são capazes de ter no seu relacionamento, e possa encontrar estratégias de entendimento.

É, no mínimo, interessante como Maldonado et a $\beta$ apresentam a questão da priorização do bebê e conseqüente desvalorização das próprias necessidades como sendo experenciada por ambos, mãe e pai, pois, em geral, percebemos na literatura uma tendência à referência somente à mulher-mãe a quem culturalmente cabe a maternagem. Os autores admitem a dedicação que o recém-nascido requer, porém lembram que o casal não deve deixar de se dedicar um ao outro, bem como de conceder tempo para outros interesses e atividades. Acreditamos que isso seja importante tanto para os casais que estejam vivenciando a experiência do filho com companheirismo, como para os que estão distanciados, no sentido de ajudá-los no enfrentamento da maneira como encaram a maternidade e a paternidade.

0 último ponto abordado nas entrevistas foi a ocupação, sobre o qual a maioria refere a pretensão de retomar os estudos ou o trabalho. Nesse sentido, nos indagamos: em que momento, efetivamente, essas mulheres irão retomar a vida pública? Ou ainda, há a consciência sobre a possibilidade de se organizar para que possam retornar à esfera pública? Esses questionamentos se fazem relevantes na medida em que a construção histórico-cultural de nossa sociedade impõe que a mulher deva permanecer no lar para cuidar do filho. Há que se fornecerem condições para que a mesma se torne cônscia de seus direitos e dos dispositivos, inclusive legais (licença maternidade, licença paternidade, licença aleitamento, salário-maternidade, regime de exercícios domiciliares), dos quais pode usufruir para a realização de uma opção consciente entre a esfera particular e a pública nesse momento.

\section{Sentimentos e sensações}

Quando questionadas sobre como se sentem e quais são os seus sentimentos nesse período, os depoimentos das mulheres recaíram sobre os seus bebês. Os sentimentos apontados foram os de satisfação, bem-estar, amor, carinho, cansaço, tristeza, alívio, preocupação com a criação e/ou futuro do bebê.

Apesar de ser notável a desvalorização de si mesma, vale lembrar que estamos discorrendo sobre mulheres que passaram nove meses pensando e ouvindo sobre seus bebês. Num espaço de tempo muito curto, esse bebê sai do imaginário da mãe e passa a ser uma realidade concreta. A princípio, seria difícil não deslocar toda a atenção para ele. Entretanto, é preciso uma mudança na mentalidade - como já começa a acontecer de forma incipiente no pré-natal e em consonância com as diretrizes do PAISM - no sentido de que o ciclo gravídico-puerperal não se limita exclusivamente à atenção ao bebê, mas, e tão importante quanto, à assistência da mulher/casal/ família. A mentalidade centrada na atenção exclusiva ao feto e, posteriormente, ao recém-nascido é decorrente de uma construção histórico-cultural que não permitiu a abertura de espaço para a exposição e discussão desses sentimentos.

Além disso, as próprias mulheres precisam perceber que o cuidado do bebê não deve ser de sua responsabilidade exclusiva e que a maternidade não é uma obrigação feminina ${ }^{15}$, sendo importante envolver, por exemplo, o parceiro, para que ela possa se dedicar a outros interesses também. Com o intuito de auxiliar nessa compreensão, vale ressaltar a afirmação de Chorodow $^{16: 28}$ de que o importante para a criança é a qualidade do cuidado, e não quem o dá.

No que diz respeito a essa categoria, esperávamos encontrar resultados que refletissem as facilidades e as dificuldades que esse período poderia lhes estar provocando. Entretanto, isso não foi constatado. Verificamos que a maioria delas nega ter tido alguma dificuldade, apesar de terem pontuado alguns problemas em suas falas. Apareceu, ainda, de forma implícita, a associação direta entre maternidade e necessidade de desenvolvimento da capacidade de enfrentamento, ou seja, para algumas mulheres, ser mãe significa ser forte (ou estar sempre forte). É possível que a tradição e a cultura de responsabilização da mulher pelo cuidado do recém-nascido ainda esteja fortemente arraigada nos seus modos de viver. As reflexões de Santos ${ }^{16: 28}$ podem ajudar a compreender esse comportamento:

As mulheres/mães de baixa renda são sensiveis e dão importância aos bons costumes de vida, e não desconhecem os princípios de uma vida sadia. Porém, as informações relativas à saúde que Ihes chegam através dos profissionais da 
saúde e da sociedade em geral atingem-nas na forma de uma informação com culpa: sentem-se acusadas de não serem boas mães.

Neste sentido, é possível que as mulheres desse estudo tenham sentido-se receosas em expor abertamente seus reais sentimentos de cansaço, estresse, medo, ansiedade, a fim de evitar o suposto estigma. Viscott ${ }^{18: 22}$ nos apresenta um outro olhar que pode contribuir para esse entendimento: os sentimentos positivos ampliam o nosso senso de força e de bem-estar, produzindo prazer, uma sensação de inteireza, vida, plenitude e esperança. Então, se está implícito em suas falas que "precisam" ser fortes, é natural que se apresentem de forma positiva diante das dificuldades da maternagem no puerpério.

Viscott ${ }^{18: 17}$ traz, ainda, uma reflexão acerca da consciência de nossos sentimentos, a qual pode nos auxiliar a direcionar a assistência à puérpera: aquilo que sentimos a respeito de qualquer coisa reflete nossa história e desenvolvimento, nossas influências passadas, nossa agitação presente e nosso potencial futuro. Partindo desse pressuposto, entendemos que se a mulher, por exemplo, nesse momento, abdica de alguns sentimentos, então, isso se refletirá no seu futuro com a manutenção dessa postura de anulação. Em contrapartida, 0 acolhimento dessa mulher, incluindo 0 estímulo à exposição e entendimento do que sente, pode possibilitar uma mudança em sua postura de enfrentamento nesta e em outras situações da vida.

Diante do exposto, percebemos um contraponto entre as influências da cultura e a consciência dos sentimentos. Isso significa que, por um lado, trata-se de uma construção histórica sobre o papel da mãe/ mulher que caracterizamos anteriormente de "mito da mãe perfeita", em que a mulher é dotada de um "poder" que lhe permite tudo suportar. Por outro lado, Penna ${ }^{14: 34}$ nos auxilia com a outra conotação sobre esse "poder materno":

A consciência da maternidade e a decisão de assumi-la plenamente dão à mulher um sentimento de poder. A mulher sente-se realmente poderosa (...). É um sentimento de plenitude. Outras mulheres têm a sensação de universo, de grandiosidade, como se o mundo se abrisse e se expandisse sobre elas.

Na primeira interpretação apresentada, esse poder apresenta-se como uma imposição sócio-cultural, que foi internalizada pela mulher. Já na segunda explicação, a mulher, ao olhar para dentro de si, assume conscientemente a sua maternidade e se sente fortalecida. Apesar de essa última consideração poder estar presente no interior das mulheres entrevistadas, os sentimentos expostos e a maneira como foram expressos em seus depoimentos nos fazem acreditar que a construção do referido "poder materno" está mais associado à pressão social do que a uma atitude consciente sobre a maternagem. Nesse sentido, é importante incluir na assistência a essa mulher 0 acolhimento sem julgamento e o estímulo para que ela possa formular uma opção autêntica no que diz respeito ao seu papel de mulher/mãe.

Isto reflete-se também na sua forma de lidar com o próprio corpo. Apesar de as puérperas terem se referido aos seus corpos, na maior parte das entrevistas, apenas quando questionadas, de uma forma ou de outra, elas percebem seus corpos e as mudanças que nele estão ocorrendo (aparecimento de estrias, abdome saliente e sobrepeso decorrentes da gravidez), mostrando-se, inclusive, dispostas a contornar a situação. Apesar de ter sido referida uma boa relação e cuidado com o corpo, esse é, ainda, o momento de cuidado do filho em detrimento do seu autocuidado. Isso nos faz refletir sobre o significado da anulação à qual nos reportamos. Quer dizer, esses resultados apontam para o fato de que elas se percebem sim, mas a questão maior recai sobre a desvalorização dessa autopercepção ou a nãoconscientização da dimensão e importância do que sentem sobre si mesmas e o que se passa a sua volta. Isso nos suscita uma indagação: quando é que ela passará à ação? Ou seja, quando ela valorizará essa preocupação - a princípio, com o corpo - o suficiente para que consiga fazer algo efetivamente?

Constatamos também a existência de dúvidas e receio sobre a regressão ao corpo pré-gravídico, incluindo a relação sexual. Afonso ${ }^{1}$, que também verificou em sua pesquisa com puérperas dificuldades no relacionamento sexual com o cônjuge desde 0 nascimento do filho, aponta alguns aspectos: a possibilidade da desmotivação da mulher para a relação sexual devida às modificações fisiológicas e psicológicas e ao cuidado com o recém-nascido; a crença no mito da ocorrência de danos irreversíveis nos órgãos genitais femininos por parte do casal; o homem não percebendo o desejo na mulher, sente-se pouco à vontade, ou até culpado, com os seus desejos e gera na mulher a sensação de não mais ser atraente e desejável. Portanto, é importante estimular a mulher, e se possível o casal, a dialogar sobre os seus sentimentos, desejos, dúvidas, evitando desajustes no relacionamento. 
Segundo Maldonado et $a^{\beta}$, a questão do corpo e a relação sexual devem ser discutidas na revisão pósparto. Discordamos disso, pois, como já mencionamos anteriormente, consideramos fundamental que essa temática seja também abordada com a mulher/casal durante o pré-natal, para que tenham oportunidade de reflexão e diálogo anterior ao momento crítico em si, podendo evitá-lo ou reduzi-lo.

\section{CONCLUSÃO}

A vivência do pós-parto domiciliar pelas mulheres que participaram deste estudo foi experienciada com satisfação por serem mães de bebês saudáveis e sem maiores dificuldades. Contudo, o aspecto mais relevante implícito nos seus depoimentos foi a desvalorização do ser mulher e do autocuidado em função da prioridade de atenção ao cuidado do recém-nascido.

Hajam vistas as conquistas femininas, é desejável atenuar a responsabilidade total e resignada da mulher pelo cuidado do filho, acumulada com as tarefas do lar e as atividades da esfera pública. Assim, é preciso desconstruir o "mito da mãe perfeita", estimulando, durante todo o processo gravídico-puerperal, a participação e colaboração ativa da família como um todo, na função maternal.

\section{Referências}

1. Afonso E. 0 pós-parto: dificuldades vividas pela mulher e apoio encontrado [dissertação de mestrado] [on line] 2002; [citado 7 nov 2004] [aprox.16 telas]. Disponível em: http://homepage.oninet.pt

2. Ministério da Saúde (BR). Parto, aborto e puerpério: assistência humanizada à mulher. Brasília (DF); 2001.

3. Maldonado MT, Nahoum JC, Dickstein J. Nós estamos grávidos. $7^{\text {a }}$ ed. Rio de Janeiro (RJ): Bloch; 1987.

4. Maldonado MT. Psicologia da gravidez. $16^{a}$ ed. São Paulo (SP): Saraiva; 2002.

5. Ministério da Saúde (BR). 2004 Ano da mulher [manual on line] 2004; [citado 21 out 2004] [aprox.186 telas]. Disponível em: http:/ /dtr2001.saude.gov.br/bvs/publicacoes/2004_anodamulher.pdf.

6. Minayo MCS, organizadora. Pesquisa social: teoria, método e criatividade. $9^{a}$ ed. Petrópolis (RJ): Vozes; 1998.
Tendo como um dos objetivos do acompanhamento pós-parto alcançar com profundidade, a subjetividade dessas mulheres, pensamos que uma ou duas consultas com um profissional de saúde, na maior parte das vezes desconhecido, podem não ser suficiente para que se sintam à vontade na exposição de seus reais sentimentos e para a abordagem do empoderamento sobre si mesmas. Além disso, se o protagonismo dessas mulheres for exercitado durante o pré-natal, então, é possível que no puerpério as mesmas estejam mais aptas a se assumirem como mulheres, além de mães, nesse momento.

Acreditamos ser importante caminhar no sentido de uma assistência à mulher no pós-parto que the proporcione a oportunidade de vislumbrar e buscar alternativas de enfrentamento das situações cotidianas, como protagonistas do processo decisório de maneira livre e crítica, valorizando os seus interesses e desejos não exclusivos ao bebê, sem culpa ou receio.

Pensamos que a consulta coletiva de enfermagem no pós-parto, juntamente com a consulta individual, seja uma estratégia interessante para superar esses impasses. 0 ambiente de igualdade, solidariedade e socialização de experiências/conhecimentos criado com a consulta coletiva proporciona um espaço para se abordarem esses aspectos e outros derivados da subjetividade das puérperas.

7. Nogueira MI. Assistência pré-natal: prática de saúde a serviço da vida. São Paulo (SP): HUCITEC; 1994.

8. Ministério da Saúde (BR). Resolução n 196 de 10 de outubro de 1996. Diretrizes e normas regulamentadoras da pesquisa envolvendo seres humanos. Brasília (DF): Conselho Nacional de Saúde; 1996.

9. Demo P. Introdução à metodologia de ciência. $2^{\mathrm{a}}$ ed. São Paulo (SP): Atlas; 1987.

10. Triviños ANS. Introdução à pesquisa em ciências sociais: a pesquisa qualitativa em educação - o positivismo, a fenomenologia, o marxismo. São Paulo (SP): Atlas; 1987.

11. Bardin L. Análise de conteúdo. Lisboa (PT): Edições 70; 1979.

12. Canteiro EEL, Martins MFSV. A maternidade: crenças e tradições em territórios amostra do distrito de Braga. 0 passado, o presente. Que futuro? Anais do Congresso da Associacão de Demografia Histórica [anais eletrônicos] 2004; [citado 7 nov 2004] [aprox.19 telas]. Disponível em: http://www.ugr.es/ adeh/comunicaciones/ Lopes_Canteiro_E_E.pdf. 
13. Figueiredo NMA, Santos I. Nascendo para aprender: entendendo o cuidado em saúde e enfermagem. Esc Anna Nery Rev Enferm 2000 ago; 4 (2): 235 - 42.

14. Penna MMS. Cartas a uma jovem mãe. Rio de Janeiro (RJ): Imago; 1998.

15. Lopes GT, Portella VB, De Lima ML; Penna LHG. Construindo uma proposta terapêutica de enfermagem no pré-natal de baixo risco. Esc Anna Nery Rev Enferm 2000 abr; 4 (1): 115-28.

16. Chorodow N. Psicanálise da maternidade: uma crítica a Freud a partir da mulher. In: Santos IMM. Maternagem e 0 atendimento à criança e à sua mãe. Enferm Atual 2004 jan/fev; 19: 27-30.

17. Santos IMM. Maternagem e 0 atendimento à criança e à sua mãe. Enferm Atual 2004 jan/fev; 19:27-30.

18. Viscott D. A linguagem dos sentimentos. $17^{\mathrm{a}}$ ed. São Paulo (SP): Summus; 1982.

\section{Sobre as Autoras}

\section{Lucia Helena Garcia Penna}

Professora Titular do Departamento Materno-Infantil da Faculdade de Enfermagem da Universidade do Estado do Rio de Janeiro (UERJ). Doutora em Saúde da Criança e da Mulher (IFF - FIOCRUZ)

\section{Joana labrudi Carinhanha}

Professora Assistente da Faculdade de Enfermagem da Universidade Severino Sombra (Vassouras/RJ). Enfermeira do Instituto de Psiquiatria da Universidade do Brasil (IPUB-UFRJ). Especialista em Enfermagem Obstétrica (UERJ)

\section{Raquel Fonseca Rodrigues}

Professora Substituta da Faculdade de Enfermagem da Universidade do Estado do Rio de Janeiro (UERJ). Enfermeira do Instituto Fernandes Figueira (IFF-FIOCRUZ). Especialista em Enfermagem Obstétrica (UERJ). 